\title{
Research on the Value of Promoting Jinggangshan Spirit under the Background of New Era
}

\author{
Xiangyong Tian \\ Sichuan University, Academy of Marxism, Chengdu, Sichuan, 610207, China
}

Keywords: new era; Jinggangshan Spirit; value; countermeasure

\begin{abstract}
The Jinggangshan road is a revolutionary road different from that of the Soviet Union. It is a road of "urban encircling the city and armed with power." Mao Zedong was the pioneer and founder of this road. He initially applied the revolutionary road theory of Marxism-Leninism to the practice of Chinese revolution. The successful opening of the road blew the horn for the destruction of all reactionaries. The Jinggangshan spirit has an original revolutionary national spirit with profound connotations. It is the precipitation and crystallization of the fine traditions and humanistic spirit of the Chinese nation in the revolutionary war years. In the context of the new era, it is required to take the important speech of General Secretary Xi Jinping on the spirit of Jinggangshan as a guide, staying true to the initial heart, keeping in mind the mission, and constantly injecting fresh blood into the Jinggangshan spirit.
\end{abstract}

\section{Introduction}

On February 2, 2016, General Secretary Xi Jinping came to Jiangxi for an inspection. He climbed Jinggangshan for the third time, pursued the footprints of the Chinese revolution, reviewed the hard exploration of the Chinese revolutionary road, and deeply understood the profound connotation of the Jinggangshan spirit. The great practice of the Jinggangshan revolutionary road plays an important role in the development of the Chinese revolution and the Chinese Communist Party. Finally, Xi Jinping elaborately described the spirit of Jinggangshan in the new era. "Strively pursue the ideals, seek truth from facts, seek new roads, struggle through hard work, rely on the masses to seek victory, and let Jinggangshan spirit radiate a new era of light."[1]

\section{The Social and Historical Conditions of Jinggangshan Spirit}

Marx and Engels pointed out: "The tradition of all the dying ancestors is entangled with the living mind like a dream." This sentence strongly confirms the historical inheritance of social consciousness, as well as the inheritance of the spirit. The Chinese civilization has a long history, a strong cultural heritage, and the power of cultural inheritance, which is deeply embedded in the vitality and creativity of the Chinese nation. Mao Zedong pointed out: "The Chinese nation is not only known for its hard work and hard work, but also a nation that loves freedom and is rich in revolutionary traditions. Therefore, the Chinese nation is a nation with a glorious revolutionary tradition and an excellent historical heritage." [2] He promoted the Chinese traditional culture to a deeper level. The Chinese Communists, represented by Mao Zedong, have a deeper understanding of China's specific national conditions, social contradictions, and people's expectations. Their revolutionary practice was born in the fertile soil of China's excellent traditional culture, especially Comrade Mao Zedong, "Twenty Well-known historical documents such as the Four History, Sun Tzu's Art of War, and the Romance of the Three Kingdoms are very well understood, especially for the success and failure of previous peasant wars. It is based on the influence and influence of traditional culture, Mao Zedong in 19279 After the failure of the attack on Changsha in the month, he arbitrarily led the troops to Jinggangshan and opened up the first base of the Chinese revolution. In the revolutionary struggle of Jinggangshan, a revolutionary road of "the countryside surrounded the city and the armed forces seized the political power" came out. The Jinggangshan spirit that was nurtured and produced during the Jinggangshan period is deeply rooted in the history and culture of 
China.

Lenin once said: "Without the theory of revolution, there will be no revolutionary movement." The interaction between this theory and the revolution led the establishment of the first socialist country in the economically backward Russia. The successful practice of the Russian road enlightened the advanced benevolent people who saved the country and saved the people at that time. With the outbreak of the May Fourth Movement and the introduction of early Marxism, the Communists represented by Li Dazhao and Chen Duxiu began to study and disseminate Marxism and translate communist books. , the establishment of the Communist Party group and so on. In 1918, during his tenure as a librarian at Peking University, Mao Zedong began to have the opportunity to contact and learn Marxism-Leninism. It was during this period that contact with Marxism influenced Mao Zedong's life. During the Jinggangshan period, the revolutionary road of "the countryside surrounded the city, the armed forces seized the political power", the establishment of the first Red Army of Chinese workers and peasants, and the promulgation of the first land law, "Jinggangshan Land Law", these early revolutionary explorations were based on Comrade Mao Zedong. The representative of the Chinese Communists tried to find a new democratic revolutionary road suitable for China's development. In this sense, the road to Jinggangshan was created 10 years after the outbreak of the October Revolution. After eight years of the May Fourth Movement, the Jinggangshan struggle was the inheritance and development of the October Revolution and the May Fourth Movement. It is Marxism in China. The opening of the new-democratic revolutionary road in China is marked by the glorious work of Comrade Mao Zedong.

Practice is the basis and premise of understanding, and the practice of revolution is the premise of revolutionary theory. The reason why Marx, Engels, Lenin, and Stalin were able to guide the communist movement, in addition to their genius ability, was that they personally participated in the revolutionary struggle and revolutionary practice of the time. Without revolutionary theory and revolutionary practice, no genius could Successful. In particular, Comrade Lenin, under the guidance of advanced revolutionary theories, established the first socialist country in Russia, so that some countries oppressed and enslaved saw hope. The practice of the Soviet-Russian revolutionary road gave the Chinese Communists a guiding light. The Jinggangshan struggle was practiced in the "Left" and right-wing repeated wrong struggles, and the young Chinese Communist Party paid a painful price. Mao Zedong made an important conclusion during the Jinggangshan period. "There is no right to speak without investigation", "The victory of the Chinese revolution depends on Chinese comrades to understand the Chinese issue", and "the fire of the stars can poke the original". These important conclusions give the early revolutionaries and the Chinese people the ideal and conviction. Without the revolutionary practice of the Chinese Communists' "armed workers and peasants" during the Agrarian Revolutionary War, they did not open up the courage and courage of the bases in the weakly controlled areas of the enemy. A group of determined revolutionary ideals and convictions will not be able to produce a new democratic road theory suited to the Chinese revolution. It is impossible to build a new China for 28 years of hard work, and there will be no countless revolutionary martyrs and blood.

\section{The Basic Connotation of Jinggangshan Spirit}

Pioneering and Innovating New Road is the core content of Jinggangshan spirit, and seeking truth from facts is the soul of Jinggangshan spirit. After the defeat of the Great Revolution, in the face of the brutal suppression of the white terror of the Kuomintang army, the young Chinese Communists faced various questions and choices. Where should the Chinese revolution go? What kind of path does the Chinese revolution take? Can China's red regime exist? These doubts have no ready-made answers in the classic literature of Marxism-Leninism. The revolutionary practice of the October Revolution and the Paris Commune is "urban centralism." However, the leaders of the early party advocated copying the experience of "urban centralism" and proceeding to Nanchang. The uprising, the Changsha uprising, and the Guangzhou uprising attacked the central city with strong enemy control. After the defeat of Changsha, the Chinese Communists represented by Mao 
Zedong were not only books, not only, and brave in innovation. They resolutely led the troops to Jinggangshan, opened up China's first rural revolutionary base, and prevailed Marxism in the party. The dogmatic and communist international resolutions and the erroneous tendency of the Soviet experience were resolutely waged. For the first time in the Jinggangshan period, the "ideology line" was put forward in the party, calling on everyone to emancipate their minds, seek truth from facts, and investigate and study. Without investigation, they have no right to speak and oppose the book.

Firmly convinced that the spirit of Jinggangshan can develop and innovate, and it is the endogenous driving force for the development of Jinggangshan Spirit and Jinggangshan Road. The ideal and belief is like a banner. The banner is not raised high. What about the pioneering and innovative Jinggangshan road? What about the Jinggangshan spirit produced during the Jinggangshan struggle period? Therefore, a firm ideal and belief determines the direction of the Chinese revolution, and it is a beacon that will never be erased in the hearts and minds of the military and the people, and determines the political orientation of the Jinggangshan spirit. During the Jinggangshan period, the army and the people believed in communism very firmly. Although they could not really understand the Marxist text, they knew that the Communist Party of China was a group that worked for the poor people and was a party that struggled for the liberation of the whole country. They are the first to be fearless, not afraid of death, not to compare, not to love the spirit, the heroic spirit that is willing to sacrifice for the Chinese revolution and communism is deeply embedded in the spirit of Jinggangshan. In the new era, our main contradictions have changed, and the people's pursuit of material life has gradually turned into a yearning for a better life and a demand for the spirit. How can we re-promote Jinggangshan in the new era to uphold the spirit of ideals and convictions? This is to consider the Jinggangshan spirit and the factors of the times.

Hard work and selfless dedication are the important content and concrete manifestation of Jinggangshan spirit, and it is the essential spiritual quality for the creation of Jinggangshan Road. In his speech commemorating the 80th anniversary of the victory of the Red Army's Long March, General Secretary Xi Jinping pointed out that the stormy snow and frost can not help the heroic Chinese Red Army, hunger and cold to force the body of the soldiers, the revolutionary ideal is higher than the sky. During the Jinggangshan period, the spirit of hard work and selfless dedication of the military and civilians was concentrated as: "For the sake of the interests of the people and the needs of the revolutionary cause, the Communists took the lead to eat hardships, and shared difficulties with the military and civilians, strictly implementing the three disciplines and eight points of attention, except The Communists of the people's interests did not have any special interests of their own. It is very difficult. However, the early Communists were not intimidated by the difficulties. Without the salt, the vast numbers of soldiers and civilians organized the masses to control the salt and salt. Without guns and ammunition, they would fight the iron ordnance institutes themselves. Without drugs, they would lead the masses to go up the mountain to collect herbs. In the absence of clothing and food, the heroic Jinggang children still maintain an optimistic spirit and a hard-working style. At that time, there was a song in the Jinggangshan base: red rice, pumpkin soup, autumn eggplant, delicious flavor, and the meal was eaten well; dry straw, soft and yellow, gold silk was covered, not afraid of north wind and heavy snow, warm Warm and dream. In the face of such a difficult environment, Jinggang's children are still able to make fun of themselves. This is where the great Jinggangshan spirit lies.

\section{To Promote the Value of Jinggangshan Spirit in New Era}

Strengthening ideals and convictions is the spiritual pillar of a country and a nation. "I don't want to stand, the world can't do anything." It is this spirit that supports the unremitting drive of a nation's pursuit of progress and struggle. Throughout the ages, a regime or a nation that lacks ideals and convictions has no leader, lacks the goal of struggle and enterprising spirit. In October 1927, the early communists represented by Mao Zedong, without a firm communist conviction, firmly believed in the revolutionary situation of "the fire of the stars, can poke the original", firmly believed that encircling the city in the countryside is the only correct path in China, and firmly 
believes that the Chinese Communist Party is the most Revolutionary, the most capable political party. Then China's new democracy cannot achieve complete victory. It is this firm ideal and belief that has become the soul of Jinggangshan spirit and laid the foundation of Chinese revolutionary culture.

In the new era, we must build a well-off society in an all-round way and realize the Chinese dream of the great rejuvenation of the Chinese nation. To reach the center of the world stage, we still need to have the ideals and beliefs of the new era. In the past 40 years of reform and opening up, China's overall national strength has increased significantly, but China's population has a large base and the per capita total cannot be compared with most countries in the world. The basic national conditions in which China is still in and will be in the primary stage of socialism have not changed. This requires us to persist and not to surpass or leave the primary stage of socialism. As Xi Jinping discussed in the report of the 19th National Congress: "The whole party must firmly grasp the basic national conditions of the primary stage of socialism and firmly base itself on the greatest practical stage of socialism... to build China into a prosperous, strong, democratic, civilized, harmonious and beautiful Struggling for a socialist modernization power."[3]

Innovation is the unremitting driving force for the development of a nation and a country. It is also the source of a ruling party's vitality and long-term governance. Chinese culture has a long history, and the industrious Chinese nation has created a splendid civilization. Technological inventions such as gunpowder, compass, and papermaking have greatly promoted world progress. However, since the modern times, due to China's closed-door country, economic stagnation, and self-restraint, imperialism has opened the door to China by force and suffered trampling and embarrassment for nearly a century. The founding of the Communist Party of China was a big event that opened up the world. Under the leadership of the Communist Party of China, it gradually stepped out of the road model different from the Soviet Union's "city center theory". In the Jinggangshan period, Mao Zedong was the early leader of the party, and the situation was judged by time. It has created a new road for the Chinese revolution to encircle the city with the countryside and to seize the political power. The dare to take the new road is the core of the revolutionary spirit of Jinggangshan. It is the courage and courage of dare to take a new road. The Chinese revolution has gradually become weaker and stronger, and rural areas have gradually occupied the city.

Entering a new era, our socialist construction with Chinese characteristics has entered a new stage of development. How can China achieve better and permanent development? We have no ready-made blueprints and no existing countries can learn from them. In the early days of reform and opening up, we were "crossing the river by feeling the stones." Now, after 40 years of reform and opening up, we must have our own development philosophy, we must have our own innovative theories, and we must have the spirit of seeking truth from facts and dare to take a new road. For new situations and new problems, we will continue to explore and resolve outstanding contradictions in the development of the market economy, seek a way out in innovation, and achieve rapid development in innovation.

The 19th National Congress of the Communist Party of China summarized the results of the arduous theory of the Party Central Committee with Comrade Xi Jinping as the core of the 18th National Congress, summed up the thoughts of socialism with Chinese characteristics in the new era of Xi Jinping, established the guiding ideology of our party for a long time in the new era, and realized the Marxist China. The theory of theory has once again kept pace with the times.

The arduous exploration of the Chinese revolution in the Jinggangshan period was the burgeoning stage of Mao Zedong Thought. The Jinggangshan spirit is an important part of Mao Zedong Thought. It is precisely because of the vigorous promotion of this Jinggangshan spirit that the Chinese revolution, construction and reform can achieve brilliant success. The Communist Party of China is the successor of Chinese traditional culture and revolutionary culture. It is also the initiator of China's excellent traditional culture and revolutionary culture. General Secretary Xi Jinping repeatedly mentioned the promotion of revolutionary culture and insisted on cultural self-confidence. A culture-confident nation must be a united nation. 


\section{Acknowledgements}

Fund Project: Sichuan University Graduate Research Innovation Fund Funded General Project "The Theoretical Exploration and Practical Experience of the Communist Party of China in the Early New China (1949-1956)” (2018YJSY043)

\section{References}

[1] "General Secretary Xi Jinping visited Jiangxi in the eve of the Spring Festival to greet the cadres and the masses”, People’s Daily, February 4, 2016.

[2] Selected Works of Mao Zedong (Vol. 2), Beijing: People's Publishing House, 1991, p. 623.

[3] Xi Jinping: "Report of the 19th National Congress of the Communist Party of China", People's Daily, October 19, 2017. 